OPEN ACCESS

Edited by: Martina De Zwaan,

Hannover Medical School,

Germany

Reviewed by: Kai G. Kahl,

Hannover Medical School, Germany Alejandro Magallares, Universidad Nacional de Educación a Distancia (UNED), Spain

*Correspondence: Bernadette Ann Murphy bernadette.murphy@uoit.ca

Specialty section: This article was submitted to

Psychosomatic Medicine, a section of the journal

Frontiers in Psychiatry

Received: 23 October 2017 Accepted: 29 January 2018 Published: 06 March 2018

Citation:

Gourgouvelis J, Yielder P, Clarke ST, Behbahani $H$ and Murphy BA (2018)

Exercise Leads to Better Clinical Outcomes in Those Receiving Medication Plus Cognitive Behavioral Therapy for Major Depressive Disorder.

Front. Psychiatry 9:37.

doi: 10.3389/fpsyt.2018.00037

\section{Exercise Leads to Better Clinical Outcomes in Those Receiving Medication Plus Cognitive Behavioral Therapy for Major Depressive Disorder}

\author{
Joanne Gourgouvelis, Paul Yielder, Sandra T. Clarke, Hushyar Behbahani \\ and Bernadette Ann Murphy*
}

University of Ontario Institute of Technology, Oshawa, ON, Canada

Objective: The aim of this study is to investigate the effects of exercise as an add-on therapy with antidepressant medication and cognitive behavioral group therapy (CBGT) on treatment outcomes in low-active major depressive disorder (MDD) patients. We also explored whether exercise reduces the residual symptoms of depression, notably cognitive impairment and poor sleep quality, and aimed to identify putative biochemical markers related to treatment response.

Methods: Sixteen low-active MDD patients were recruited from a mental health day treatment program at a local hospital. Eight medicated patients performed an 8-week exercise intervention in addition to CBGT, and eight medicated patients attended the CBGT only. Twenty-two low-active, healthy participants with no history of mental health illness were also recruited to provide normal healthy values for comparison.

Results: Results showed that exercise resulted in greater reduction in depression symptoms ( $p=0.007, d=2.06$ ), with $75 \%$ of the patients showing either a therapeutic response or a complete remission of symptoms vs. $25 \%$ of those who did not exercise. In addition, exercise was associated with greater improvements in sleep quality $(p=0.046$, $d=1.28)$ and cognitive function $(p=0.046, d=1.08)$. The exercise group also had a significant increase in plasma brain-derived neurotrophic factor (BDNF), $p=0.003$, $d=6.46$, that was associated with improvements in depression scores $(p=0.002$, $\left.R^{2}=0.50\right)$ and sleep quality $\left(p=0.011, R^{2}=0.38\right)$.

Conclusion: We provide evidence that exercise as an add-on to conventional antidepressant therapies improved the efficacy of standard treatment interventions. Our results suggest that plasma BDNF levels and sleep quality appear to be good indicators of treatment response and potential biomarkers associated with the clinical recovery of MDD.

Keywords: major depressive disorder, exercise, brain-derived neurotrophic factor, sleep quality, cognition 


\section{INTRODUCTION}

Major depressive disorder (MDD) is a global public health problem being the second leading cause of disability worldwide $(1,2)$ and projected to be the leading cause by 2030 (2). Epidemiological research suggests that $3.8 \%$ of Canadians report a depressive episode within the past year (3), and the lifetime prevalence is $12.6 \%$ (4). It has been estimated that merely half of depressed individuals seek medical treatment, and among those who do seek help, just over 30\% receive an efficacious treatment (5-9). Furthermore, over $40 \%$ of MDD patients who are considered in partial or full remission continue to experience residual symptoms and are at greater risk for relapse, highlighting the need for more efficacious antidepressant therapies $(10,11)$.

Major depressive disorder is a clinically and biologically heterogeneous disorder that frequently coexists with other medical illnesses (12). Consequently, the etiology and pathogenesis of MDD is thought to be multifaceted, making it very challenging for researchers to develop novel efficacious antidepressant therapies. Converging evidence from brain imaging and neuropathological studies in humans and animals have linked MDD to structural, functional, and cellular changes within the hippocampal formation. People with MDD have consistently been found to have reduced hippocampal volumes (13-15) and impaired hippocampal function during memory encoding and retrieval processes (16-20).

Growing evidence has suggested that reductions in neurotrophins and growth factors, particularly brain-derived neurotrophic factor (BDNF), to be a central player for both the onset of MDD and recovery once levels are normalized (21-26). BDNF is an activity-dependent secreted protein that plays a critical role in synaptic plasticity processes underlying learning and memory (27). Therapeutic interventions that augment neuroplasticity, via increases in BDNF, have been shown to reverse the pathological effects of depression (28-30). A growing body of research is also suggesting that a chronic inflammatory response may also play a role in the pathogenesis of MDD $(31,32)$. The inflammatory hypothesis of depression was founded on the common comorbidity of depression-like behaviors with systemic infection, cancer, and autoimmune diseases (33). Increased levels of proinflammatory interleukin (IL)-1 $\beta$, IL-6, and tumor necrosis factor (TNF)- $\alpha$ and decreased levels of anti-inflammatory IL-1 receptor antagonist and IL-10 are the most commonly reported cytokines in the depression literature (34-40). More recently, Moon et al. (41) identified the cysteine proteinases CTSB (CTHB) to be a novel protein that may play a key role in the beneficial effects of exercise on neural function.

Several studies have reported that exercise alone or in combination with other therapies to be as efficacious in treating mild to moderate depression with response rates similar to antidepressant medication and cognitive behavioral therapy (42-47). Furthermore, it has been shown to improve cognitive function (48) and sleep quality (49), which are the two of the most frequently reported residual symptoms among patients with MDD who achieve remission (50). Exercise for depression has also been shown to increase hippocampal volume (51) and increase serum BDNF concentrations (52) and may be a neuroprotective mechanism that maintains cognitive ability in older age (53). The beneficial effects of exercise on overall brain health have also been observed in other populations. In elderly adults, exercise protects against the development of neurodegenerative diseases (54), reverses age-associated brain volume loss $(55,56)$, improves memory performance $(57,58)$, and improves executive function (59). Exercise has also been shown to facilitate neurocognitive recovery from traumatic brain injury $(60,61)$ and increase hippocampal volume in schizophrenics (62).

The main objective of this exploratory feasibility study is to explore the effects of combining exercise as an add-on therapy with antidepressant medication and cognitive behavioral group therapy (CBGT) treatment outcomes in low-active individuals. Sedentary time has been shown to be positively associated with low-grade chronic inflammation in non-depressed populations (63), while BDNF levels are higher in cardiorespiratory fit individuals vs. unfit individuals (64). As such, the research investigating the underlying mechanism involved in the etiology and pathogenesis of MDD may be confounded by low physical activity levels and sedentary behavior time that tend to be more prevalent in depressed populations (53). For this reason, we specifically recruited low-active MDD patients and controls to control for variations in baseline fitness level. In addition to reduction in depressive symptoms, we were interested in exploring if exercise reduces the residual symptoms of depression, notably cognition and sleep quality, and identifying putative biochemical biomarkers (such as BDNF, cytokines, and CTHB) related to treatment response. These findings provide preliminary evidence, which can be used to focus future research aimed at understanding of the etiology and pathophysiology of MDD as well as indicators associated with treatment response in exercise.

\section{MATERIALS AND METHODS}

All procedures were approved by the University and Hospital Institutional Review Boards, and all participants provided written informed consent. The study was registered with Clinicaltrials. gov (\#NCT03191994).

\section{Participants}

Sixteen low-active patients (mean age $=39.31$ years, $S D=7.02$; 12 females) with comorbid MDD and anxiety were recruited from an outpatient CBGT program at a local hospital in Oshawa, Ontario, Canada. Twenty-two low-active, healthy participants (mean age $=20.63, \mathrm{SD}=1.19 ; 11$ females) with no history of mental health illness or neurological disease were also recruited from a local university in Oshawa, Ontario Canada to provide normal healthy values for comparison. Depressed participants $(n=16)$ had a confirmed diagnosis of MDD according to an unstructured clinical interview by hospital psychiatrists based on the criteria from the Diagnostic and Statistical Manual of Mental Disorders-Fourth Edition [DSM-IV-TR (65)] and a score of $\geq 20$ on the Beck Depression Inventory-Second Edition [BDI-II: A (66)]. Eligible MDD participants had no co-existing DSM-IV-TR Axis I disorders apart from anxiety. MDD participants were eligible if their pharmacological medication was stabilized a minimum of 6 weeks prior to study enrollment, experienced depression 
symptoms for a minimum of 6 months, and screened negative on the Global Appraisal of Individual Needs for substance abuse (67). MDD and healthy participants were considered low active if they exercise for less than $20 \mathrm{~min}$, three times per week. All participants were screened with the Physical Activity Readiness Questionnaire to ensure they had no medical contraindications to physical activity.

\section{Psychometric Measures: Anxiety, Depression, Sleep Quality}

The BDI-II $(66,68)$ was used to measure depression severity. The BDI-II is the most commonly used self-reported instrument that measures depression severity ranging from mild to severe. The BDI-II has excellent internal consistency, with a coefficient alpha of 0.91 (68). Depression was measured using the BDI-II (66), which is one of the most widely used self-reported instrument capable of measuring depression severity ranging from not depressed to severely depressed (68). The Hospital Anxiety and Depression Scale (HADS) was used to measure both depression and anxiety (69). The HADS is also a reliable and widely used self-reporting instrument that consists of two 7-item subscales, one measuring anxiety (HADS-A) and one measuring depression (HADS-D) that assesses feelings of anxiety and depression. The HADS-A and HADS-D have good internal consistency, with coefficient alphas of 0.83 and 0.82 , respectively (70). Poor sleep quality is one of the two most frequently reported residual symptom among patients with MDD who achieve remission (50). The Pittsburgh Sleep Quality Index (PSQI) was used to measure sleep quality during the previous month (71). The PSQI is a 19-item questionnaire that measures 7 components of sleep quality including subjective sleep quality, sleep latency, sleep duration, habitual sleep efficiency, sleep disturbances, use of sleeping medications, and daytime dysfunction. The maximum PSQI score is 21 points, and an overall PSQI score of $>5$ points indicates that the individual has poor sleep quality. The PSQI has good internal consistency, with a coefficient alpha of 0.83 (71).

\section{Cognitive Measures}

Cognitive impairment is one of the two most frequently reported residual symptoms among patients with MDD who achieve remission (50). To assess cognitive performance within selected domains, we used a computerized cognitive battery, the Cambridge Neuropsychological Test Automated Battery (CANTAB; Cambridge Cognition, Cambridge, UK; http://www.cambridgecognition. $\mathrm{com} /$ cantab/cognitive-tests/). The CANTAB is a fast and accurate method to assess cognitive functioning (72) and shown to possess acceptable to high levels of concurrent validity and test-retest reliability (73). Each test is presented on a computer touch screen and uses non-verbalizable patterns presented in a game-like format that provides immediate feedback to maintain interest and reduce boredom (74). Three CANTAB tests were included in our assessment battery that have been previously used to identify impaired cognitive function in MDD and shown to be sensitive to changes in the hippocampus and frontal lobes (75-77). The Paired Associates Learning (PAL) assesses visual learning and memory. The delayed matching to sample (DMS) assesses recognition memory for patterns. The intradimensional/extradimensional set shift (IED) is a measure of rule acquisition and reversal, often considered a test of cognitive flexibility. In addition, the Montreal Cognitive Assessment (MoCA), a brief neurocognitive tool with high sensitivity for screening patients with mild cognitive impairment, was used to assess global function. The maximum MoCA score is 30 and an overall score $\leq 25$ is indicative of mild cognitive dysfunction (78). The MoCA has good internal consistency, with a coefficient alpha of 0.83 (78).

\section{Plasma Collection}

Non-fasted venous blood was collected mid-day from each participant prior to the first exercise session and again at 8 weeks by venipuncture into ethylenediaminetetraacetic acid tubes. Blood samples were prepared within $30 \mathrm{~min}$ by centrifugation, and the fibrinogen containing plasma supernatant was stored at $-85^{\circ} \mathrm{C}$ until assayed. Plasma proteins IL- $1 \beta$, IL-1Ra, IL-6, IL-10 TNF- $\alpha$, BDNF, and total CTHB were quantified using enzyme-linked immunosorbant assays (ELISAs) following manufacturer's protocols (R\&D Systems, MN, USA; BioLegend, CA, USA). ELISA plates were read at a wavelength of $450 \mathrm{~nm}$ using a Synergy HTTR microplate reader (Bio-Tek Instrumentation, VT, USA).

\section{Fitness Assessment}

The YMCA cycle ergometer test recommended by the American College of Sports Medicine was used to measure cardiorespiratory fitness at baseline and 8 weeks (79-81). The YMCA protocol is an indirect submaximal exercise test that uses heart rate (HR) measurements to estimate maximal oxygen consumption $\left(\mathrm{VO}_{2} \mathrm{max}\right)$. The test consists of two or more consecutive 3-min stages at a given workload. The objective is to elevate the participant's HR between $110 \mathrm{bpm}$ and $85 \%$ of age-predicted maximal HR for two consecutive stages. The first stage of the test was a $25 \mathrm{~W}$ workload at 50 revolutions per minute. Radial pulse was used to measure HR during the final $15 \mathrm{~s}$ of each minute to determine the workload of the following stages. After a steady-state HR (two successive measures that differ, $<5 \mathrm{bpm}$ ) was within $10 \mathrm{bpm}$ of the $85 \%$ age-predicted maximum $\mathrm{HR}$, the test was complete. $\mathrm{VO}_{2}$ max was predicted using the YMCA formula that includes workload, body mass, and predetermined constants.

\section{Exercise Intervention}

The 8-week exercise prescription was based on the international recommendation to perform a minimum of $150 \mathrm{~min}$ per week of moderate to vigorous intensity aerobic exercise in addition to resistance activities two times per week, for developing and maintaining cardiorespiratory, musculoskeletal, and neuromotor fitness in healthy adults $(82,83)$. This minimum recommended dose of exercise was prescribed to increase participant adoption and adherence since low-active people with depression generally lack motivation to begin an exercise program (84). Also, exercise prescriptions based on this intensity performed over 6 weeks have shown to significantly improve cardiorespiratory fitness and depression symptoms in patients with $\operatorname{MDD}(85,86)$. The research has also found that a combining aerobic with resistance training is more effective than aerobic exercise alone in improving depressive symptoms and cognitive function $(87,88)$. The CBGT + exercise (exercise) group performed one aerobic 
only and two resistance (with a shorter bout of aerobic activity) weekly sessions for a duration of 8 weeks. All exercise sessions were performed alone, on non-consecutive days and each session were supervised by a qualified exercise professional to increase participant compliance and to ensure all participants fulfilled the exercise prescription (89). The exercise intensity for aerobic and resistance sessions was based on a target HR between 60 and $80 \%$ of their age-predicted maximum HR. The aerobic workloads were determined by HR response and increased by 5 -min increments over the course of the 8 weeks, reaching a maximum of $60 \mathrm{~min}$ per session. Resistance sessions incorporated a whole-body exercise prescription using the larger muscle groups, and workloads were approximately $95 \%$ of the 10 repetition maximum to ensure proper form. Resistance exercises were performed in two or three supersets (one set of each exercise with no rest between sets) with an 8-12 repetition range to decrease rest times and to maintain target HR. Radial pulse was measured throughout each exercise session to ensure that participants maintained their target HR. Attendance was recorded, and only those participants who completed $>80 \%$ of the exercise sessions were included in the analysis. For a full description of the exercise intervention, please see Ref. (90).

\section{Statistical Analysis}

All statistical analyses were conducted using GraphPad Prism, v6 (La Jolla, CA, USA). Continuous data are presented as means (SDs). Categorical data are presented as frequencies. Baseline group differences were compared using a two-tailed Student's $t$-test and Fisher's exact test. Paired $t$-tests were used to compare the pre-post change for each group, and a two-way repeated measures analysis of variance (ANOVA) was used to determine group-by-time interactions. $p$ less than 0.05 were considered statistically significant. Effects sizes were determined using a modified version of Cohen's $\mathrm{D}\left(d_{p p c 2}\right)$ method, which divides the difference in mean pre-post change between groups by the baseline pooled SD to account for any baseline differences (91). FDR correction was performed on all $p$ values for $t$-tests and ANOVAs assessing the effects of exercise to confirm that they survived correction for multiple comparisons. The criteria used to determine remission and response rates were BDI cut-off scores $\leq 11$ and $\geq 47 \%$, respectively (92). Simple linear regression analyses were performed to examine the relationship between pre-post changes in plasma BDNF levels and BDI scores, sleep quality, and correct response latency.

\section{RESULTS}

\section{Baseline Characteristics between MDD and Healthy Groups}

Analysis revealed no significant difference in gender distribution between groups $(p=0.182)$. As expected, the MDD group was significantly older than the healthy group, $t(36)=12.31, p<0.0001$, given that we intentionally recruited younger individuals to provide normative data for comparison from healthy individuals with no history of mental health illness or other confounding pathologies that increase with age. Results showed that patients with MDD had a significantly elevated BDI score, $t(36)=12.90$, $p<0.0001$; HADS-A score, $t(36)=13.07, p<0.0001$; and PSQI score, $t(36)=9.94, p<0.0001$, compared to the healthy controls. The MDD group had a significantly greater body mass index compared to the healthy group, $t(36)=2.08, p=0.045$. A single participant from the exercise group discontinued baseline $\mathrm{VO}_{2}$ max testing due to exhaustion and was excluded from the $\mathrm{VO}_{2}$ max analysis. There were no significant differences between the groups for $\mathrm{VO}_{2} \mathrm{max}, \mathrm{BDNF}$, and CTHB. Cytokine data for IL-1 $\beta$, IL-1ra, IL-6, and TNF- $\alpha$ were not included in the parametric analysis since greater than $50 \%$ of the values were below the level of detection. Therefore, we compared the frequencies of detectable cytokine concentrations between the groups using Fisher's exact test. Results showed no differences between groups in frequency of individuals with detectable circulating concentrations of IL-1 $\beta$, IL-1ra, IL-6, IL-10, and TNF- $\alpha$ ( $p>0.05)$, suggesting that depressed subjects were not displaying classical signs of systemic inflammation at the study baseline. Cognitive tests revealed that the MDD group performed significantly poorer on the MoCA, $t(36)=2.32, p=0.026$; had significantly more errors for the PAL test, $t(35)=3.90, p=0.0004$; and had a significantly longer correct response latency for the DMS test $t(35)=2.44$, $p=0.020$, suggesting cognitive impairment. Performance did not differ between groups for the DMS and IED cognitive tests $(p>0.05)$. See Table 1.

\section{Baseline Characteristics between MDD Groups}

At baseline, the exercise group had a significantly higher BDI score compared to the CBGT only (non-exercise) group, $t(14)=2.38$,

TABLE 1 | Baseline characteristics of depressed patients and healthy controls.

\begin{tabular}{|c|c|c|c|}
\hline Variables & $\operatorname{MDD}(n=16)$ & Healthy $(n=22)$ & $p$ \\
\hline \multicolumn{4}{|l|}{ Demographic } \\
\hline Sex (male/female) & $4 / 12$ & $11 / 11$ & 0.452 \\
\hline Age (years) & 39.31 (7.02) & $20.95(1.25)$ & $<0.0001$ \\
\hline \multicolumn{4}{|l|}{ Psychometric } \\
\hline BDI (depression) & $37.50(8.18)$ & $7.55(6.15)$ & $<0.0001$ \\
\hline HADS-Anxiety & $15.13(2.73)$ & $4.77(3.24)$ & $<0.0001$ \\
\hline PSQI (sleep) & $13.81(3.47)$ & $4.36(2.40)$ & $<0.0001$ \\
\hline \multicolumn{4}{|l|}{ Biological } \\
\hline Body mass index $\left(\mathrm{kg} / \mathrm{m}^{2}\right)$ & $28.79(5.17)$ & $24.89(5.17)$ & 0.045 \\
\hline $\mathrm{VO}_{2} \max (\mathrm{ml} / \mathrm{kg} / \mathrm{min})$ & $23.40(6.05)^{\mathrm{a}}$ & $21.79(7.77)$ & 0.510 \\
\hline BDNF (pg/ml) & $8,237(2,163)$ & $8,935(2,837)$ & 0.415 \\
\hline CTHB (pg/ml) & 29,253 (9066) & $37,551(14,867)$ & 0.348 \\
\hline \multicolumn{4}{|l|}{ Cognitive } \\
\hline MoCA & $24.56(1.67)$ & $26.18(2.40)$ & 0.026 \\
\hline DMS\% correct & $85.78(13.06)^{a}$ & $90.30(10.02)^{\mathrm{a}}$ & 0.241 \\
\hline DMS latency (ms) & $4817(1770)^{\mathrm{a}}$ & $3640(1176)^{a}$ & 0.020 \\
\hline PAL (errors) & $24.27(19.33)^{\mathrm{a}}$ & $7.50(5.03)^{\mathrm{a}}$ & 0.0004 \\
\hline IED (errors) & $19.07(12.41)^{\mathrm{a}}$ & $22.80(17.93)^{\mathrm{a}}$ & 0.495 \\
\hline
\end{tabular}

BDI, Beck Depression Inventory; BDNF, brain-derived neurotrophic factor; CTHB,

CTSB; DMS, delayed matching to sample; HADS, Hospital Anxiety and Depression Scale; IED, intradimensional/extradimensional shift; MDD, major depressive disorder; MoCA, Montreal Cognitive Assessment; PAL, paired associates learning; PSQI,

Pittsburgh Sleep Quality Index; $\mathrm{VO}_{2}$ max, maximum oxygen.

Data are expressed as mean (SD).

${ }^{a}$ One missing value.

$p$-Values $<0.05$ were considered statistically significant and are represented in bold. 
$p=0.032$, indicating greater depression severity. The non-exercise group had significantly higher plasma BDNF concentrations compared to the exercise group, $t(14)=2.40, p=0.031$. There were no other baseline differences between groups (see Table 2). More than $50 \%$ of the patients did not have detectable plasma cytokine concentrations and were not included in the parametric analysis. Therefore, we conducted a Fisher's exact text on the frequencies of detectable plasma cytokine concentrations and found no group differences at baseline $(p>0.05)$.

\section{Pre-post Measures for MDD Groups Depressive Symptoms}

Both MDD groups showed a statistically significant decrease in BDI and HADS-D scores following treatment. A two-way repeated measures ANOVA revealed a group-by-time interaction, $f(1,14)=10.18, p=0.007$, and a large effect size of $d=2.06$, indicating that the exercise group had a greater reduction in BDI scores compared to the non-exercise group at 8 weeks (see Figure 1A; 63 vs. $27 \%$ ). Moreover, $75 \%$ of the patients in the exercise group showed either a therapeutic response or complete remission of symptoms vs. $25 \%$ of the non-exercise group (see Figure 2).

\section{Sleep Quality}

The exercise group showed a significant decrease in PSQI scores $(p=0.010)$, while the non-exercise group showed no significant

TABLE 2 | Baseline characteristics of depressed groups.

\begin{tabular}{|c|c|c|}
\hline Variables & $\begin{array}{c}\text { CBGT + exercise } \\
(n=8)\end{array}$ & CBGT $(n=8)$ \\
\hline
\end{tabular}

\begin{tabular}{|c|c|c|c|}
\hline \multicolumn{4}{|l|}{ Demographic } \\
\hline Sex (male/female) & $1 / 7$ & $3 / 5$ & 0.248 \\
\hline Age (years) & 37.25 (8.00) & $41.38(5.66)$ & 0.253 \\
\hline Education (years) & $13.25(2.19)$ & $13.50(1.41)$ & 0.790 \\
\hline $\begin{array}{l}\text { Cumulative illness duration } \\
\text { (years) }\end{array}$ & $3.57(3.21)$ & $3.00(3.02)$ & 0.432 \\
\hline \multicolumn{4}{|l|}{ Psychometric } \\
\hline BDI (depression score) & $41.75(3.50)$ & $33.25(9.48)$ & 0.032 \\
\hline HADS-Anxiety & $15.63(1.77)$ & $14.63(3.50)$ & 0.483 \\
\hline PSQI (sleep score) & $14.38(3.46)$ & $13.25(3.62)$ & 0.535 \\
\hline \multicolumn{4}{|l|}{ Biological } \\
\hline Body mass index $\left(\mathrm{kg} / \mathrm{m}^{2}\right)$ & $28.33(5.12)$ & $29.25(5.52)$ & 0.734 \\
\hline $\mathrm{VO}_{2} \max (\mathrm{ml} / \mathrm{kg} / \mathrm{min})$ & $24.82(8.00)^{\mathrm{a}}$ & $22.16(3.80)$ & 0.416 \\
\hline BDNF (pg/ml) & $7,108.48(596.51)$ & $9,363.74(730.75)$ & 0.031 \\
\hline CTHB (pg/ml) & $37,580(10,284)$ & $48,102(25,327)$ & 0.295 \\
\hline \multicolumn{4}{|l|}{ Cognitive } \\
\hline MoCA & $24.63(1.41)$ & $24.50(2.00)$ & 0.887 \\
\hline DMS\% correct & $90.48(6.50)^{\mathrm{a}}$ & $81.67(16.23)^{\mathrm{a}}$ & 0.203 \\
\hline DMS latency (ms) & $4,857(1,648)^{a}$ & $4,781(1,983)^{\mathrm{a}}$ & 0.938 \\
\hline PAL (errors) & $22.14(20.93)^{a}$ & $26.13(19.05)^{a}$ & 0.706 \\
\hline IED (errors) & $20.57(16.09)^{a}$ & $17.75(9.04)^{\mathrm{a}}$ & 0.677 \\
\hline
\end{tabular}

BDI, Beck Depression Inventory; BDNF, brain-derived neurotrophic factor; BMI, body mass index; CBGT, cognitive behavioral group therapy; CTHB, CTSB; DMS, delayed matching to sample; HADS, Hospital Anxiety and Depression Scale; IED, intradimensional/extradimensional shift; MoCA, Montreal Cognitive Assessment; PAL, paired associates learning; PSQI, Pittsburgh Sleep Quality Index; $\mathrm{VO}_{2}$ max, maximum oxygen consumption.

Data are expressed as mean (SD).

aOne missing value.

p-Values $<0.05$ were considered statistically significant and are represented in bold. change $(p=0.09)$. There was also a significant group-by-time interaction, $f(1,14)=4.81, p=0.046$, and an effect size of $d=1.28$, suggesting that exercise was effective in improving sleep quality (see Figure 1B).

\section{Biological Markers}

There was no group-by-time interaction for $\mathrm{VO}_{2} \max$ pre-post. However, the exercise group showed a $31 \%$ increase in $\mathrm{VO}_{2} \max$ that was marginally significant $t(6)=2.17, p=0.073$, suggesting that the exercise intervention was successful at improving cardiorespiratory fitness (see Table 3). Biochemical marker analyses revealed a significant increase in plasma BDNF levels for the exercise group at 8 weeks with a group-by-time interaction $[f(1,14)=12.47, p=0.003]$ and a large effect size of $d=6.46$ (see Figure 1C). There were no pre-post changes in CTHB or cytokines in either group. A simple linear regression revealed that changes in BDNF were significantly associated with changes in BDI and PSQI scores, indicating that those who experienced a greater increase in BDNF also experienced greater improvement in depression and sleep quality (see Figure 3). No significant relationship for changes in BDNF and correct response latency was found $(p=0.190)$.

\section{Cognition}

There were no changes in performance for the MoCA, DMS, PAL, or IED tasks for either group at 8 weeks. A two-way repeated measures ANOVA revealed a group-by-time interaction for the DMS correct response latency $[f(1,13)=4.85, p=0.046]$ and a large effect size of $d=1.08$, indicating that the exercise group was significantly faster in making a correct decision postintervention (see Table 3).

\section{DISCUSSION}

This feasibility study investigated the effects of an 8-week exercise prescription, based on the minimal recommended dose and on a series of symptom, biochemical, and cognitive measures. Our preliminary study provides evidence that exercise as an add-on therapy led to higher remission/treatment response rates vs. more common treatment approaches alone. In addition, we found that exercise improves sleep quality and cognitive function, and BDNF levels increased in the exercise group posttreatment. These changes in BDNF were significantly associated with symptom improvement in depression and sleep quality scores, providing potential biomarkers of treatment response. We also did not observe any significant differences between MDD patients and healthy controls for plasma CTHB, anti-inflammatory and proinflammatory cytokines, and no changes pre-post, suggesting BDNF may be a specific marker for the positive changes, which come about following an exercise intervention in patients who do not have comorbid inflammation.

Our results provide evidence for the therapeutic use of exercise in treating MDD collaborating with previous findings that exercise as an add-on therapy to ADM is more efficacious in alleviating MDD symptoms than ADM alone $(93,94)$. While the sample in our study was small, the added benefit of an exercise 
A

CBGT + Exercise

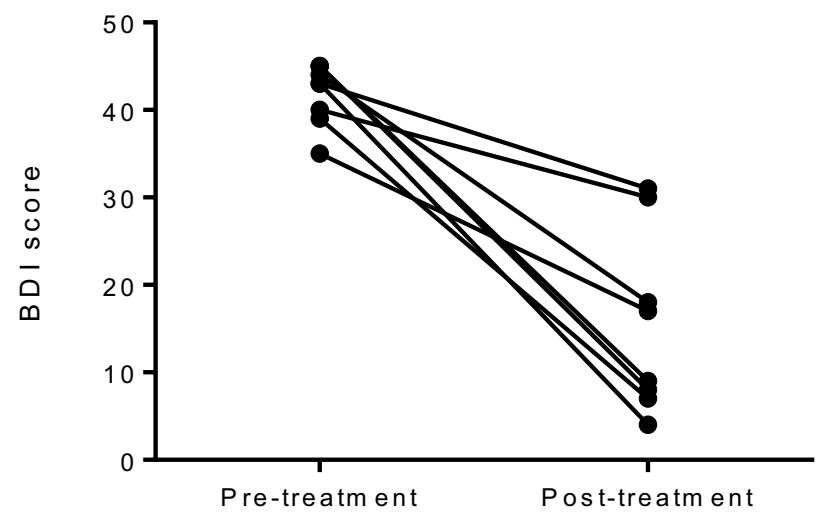

B

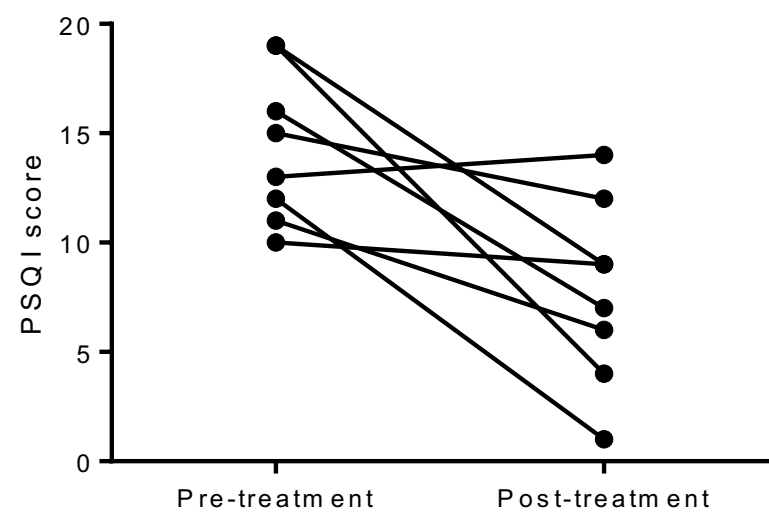

C
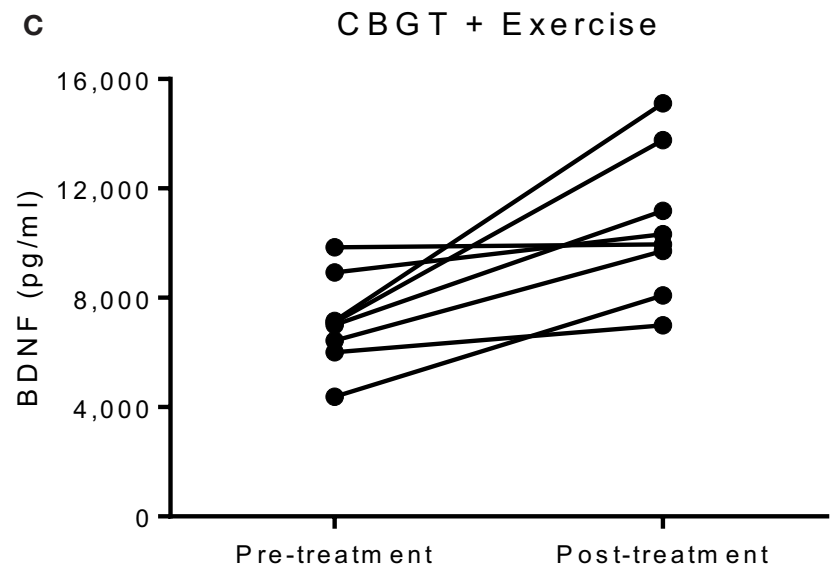

C B G T

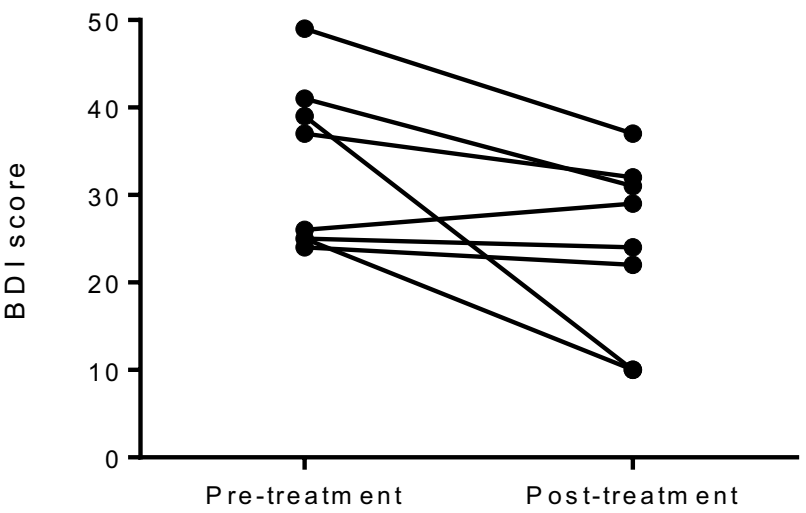

Time (weeks)

C B G T

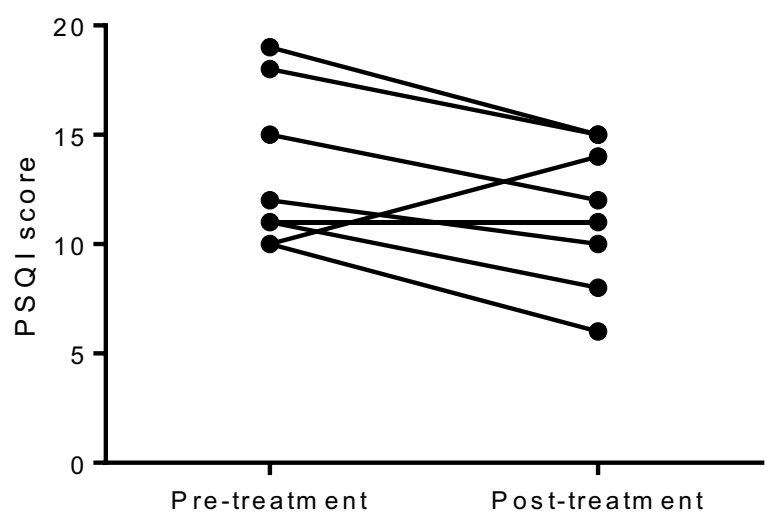

C B G T

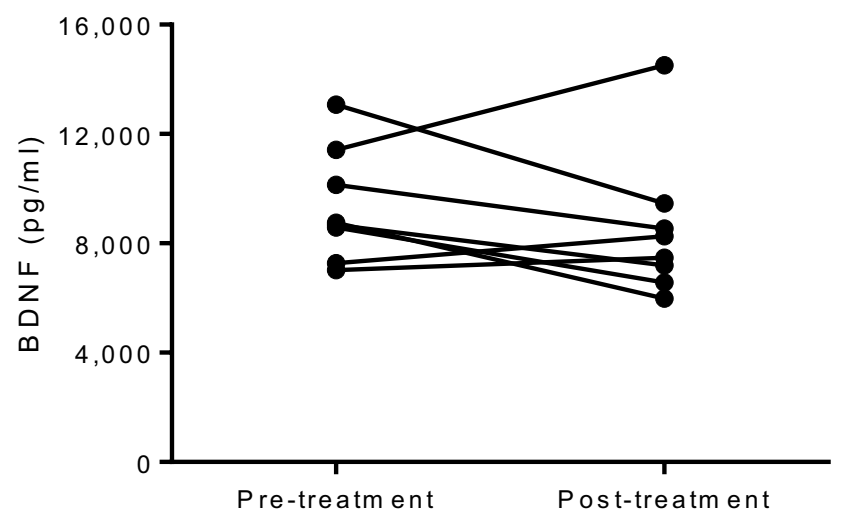

FIGURE 1 | Individual group plots illustrating pre-post changes for (A) BDI depression scores, (B) PSQI scores, and (C) BDNF levels. BDI, Beck Depression Inventory; BDNF, brain-derived neurotropic factor; CBGT, cognitive behavioral group therapy; PSQI, Pittsburgh Sleep Quality Index. 
intervention had a large effect size with respect to the changes in clinical scores. The efficacy of exercise is further substantiated by the fact that $75 \%$ of the patients in the exercise group achieving either remission or a therapeutic response vs. only $25 \%$ in the non-exercise group. This represents substantive improvement in outcomes with the addition of a relatively low-cost add-on intervention.

To the best of our knowledge, this is the first study to investigate the effects of exercise in combination with ADM and CBGT specifically in a low-active MDD population. As such, there are limited data to compare our research findings. The molecular link between exercise and depression is not well understood but may

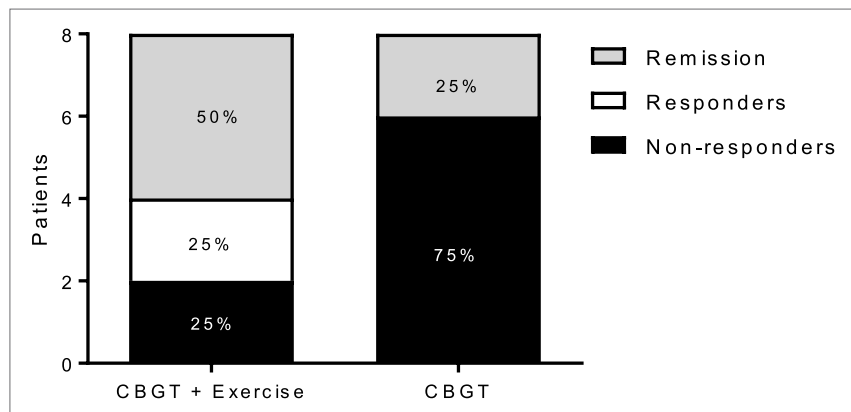

FIGURE 2 | Responders, non-responders, and remissive MDD patients at 8 weeks for each group. Treatment response and remission rates were greater for the exercise group $(N=6)$ compared to $(N=2)$ for the nonexercise group. Responders represent patients with a greater than or equal to a $47 \%$ reduction $\mathrm{BDI}$ score at 8 weeks compared to baseline, and remission represents patients with a BDI score less than or equal to 11. BDI, Beck Depression Inventory; CBGT, cognitive behavioral group therapy; MDD, major depressive disorder. be partly mediated by increases in neurotrophic growth factors that promote neuroplasticity, particularly BDNF. Consistent with the exercise-induced increase in BDNF observed in our sample, the rodent literature has shown exercise to increase hippocampal BDNF $(95,96)$; enhance adult neurogenesis $(97,98)$, synaptogenesis (99), and angiogenesis (100); improve dendritic morphology $(101,102)$; and enhance learning and memory (103). However, in humans, the link between exercise and BDNF is less clear. Acute exercise has consistently been shown to increase peripheral BDNF levels in healthy (104-106), those with MDD $(107,108)$, and elderly (109) individuals, whereas the long-term effects of exercise on resting BDNF concentrations have been mixed $(64,110)$. Exercise has also been shown to reduce systemic inflammation in other pathological conditions such as cardiovascular disease and type 2 diabetes mellitus (111-113). Studies have reported a simultaneous increase in the systemic levels of cytokines with anti-inflammatory properties including IL-10 and IL-1 ra and a decrease in the pro-inflammatory cytokines IL-6 and TNF- $\alpha(114,115)$.

The increase in plasma BDNF concentration and the associated decrease in depressive symptoms and improvements in sleep quality observed in the exercise group adds further support to the interplay between depression, sleep quality, and BDNF that may underlie the onset and recovery of MDD (116). Sleep disturbances are reported by up to $90 \%$ of depressed subjects $(117,118)$, and sleep studies have shown that depression is associated with reductions in slow-wave activity (SWA), a reliable EEG marker of sleep homeostasis $(119,120)$. SWA is an essential mechanism for restoring synaptic plasticity processes associated with learning and memory $(121,122)$. BDNF is necessary for the birth, survival, and function of neurons in the adult brain (123-126). Furthermore, BDNF is a mediator of activity-dependent synaptic

TABLE 3 | Pre-post changes for depressed groups.

\begin{tabular}{|c|c|c|c|c|c|c|c|c|c|c|c|}
\hline \multirow[t]{2}{*}{ Measure } & \multicolumn{4}{|c|}{ CBGT + exercise $(n=8)$} & \multicolumn{4}{|c|}{ СBGT $(n=8)$} & \multicolumn{3}{|c|}{ Between-group analysis } \\
\hline & Pre, mean (SD) & Post, Mean (SD) & $p$ & $d$ & Pre, mean (SD) & Post, mean (SD) & $p$ & $d$ & $\mathbf{F}$ & $p$ & $\boldsymbol{d}_{p p c 2}$ \\
\hline \multicolumn{12}{|l|}{ Psychometric } \\
\hline $\mathrm{BDI}$ & $41.75(3.50)$ & $15.50(10.43)$ & $0.0004^{\star}$ & 2.89 & 33.25 (9.48) & $24.38(10.01)$ & 0.042 & 0.91 & 10.80 & $0.007^{\star}$ & 2.38 \\
\hline HADS-Depression & $13.63(2.97)$ & $5.88(2.23)$ & $<0.0001^{\star}$ & 2.86 & $12.00(3.59)$ & $9.75(3.73)$ & 0.034 & 0.61 & 20.91 & $0.0004^{\star}$ & 1.63 \\
\hline HADS-Anxiety & $15.63(1.77)$ & $11.38(4.53)$ & $0.010^{\star}$ & 0.90 & $14.63(3.50)$ & $11.25(2.38)$ & 0.030 & 1.11 & 0.253 & 0.623 & 0.31 \\
\hline PSQI (sleep) & $14.38(3.46)$ & $7.75(4.20)$ & $0.011^{\star}$ & 1.68 & $13.25(3.62)$ & $11.38(3.30)$ & 0.090 & 0.54 & 4.81 & 0.046 & 1.32 \\
\hline \multicolumn{12}{|l|}{ Biological } \\
\hline $\mathrm{BMI}\left(\mathrm{kg} / \mathrm{m}^{2}\right)$ & $28.33(5.12)$ & $28.29(4.48)$ & 0.934 & 0.01 & $29.25(5.52)$ & $29.95(5.36)$ & 0.068 & 0.13 & 1.84 & 0.196 & 0.14 \\
\hline $\mathrm{VO}_{2} \max (\mathrm{ml} / \mathrm{kg} / \mathrm{min})$ & $24.82(8.00)^{a}$ & $32.52(10.12)^{a}$ & 0.073 & 0.83 & $22.16(3.80)$ & $26.42(8.17)$ & 0.130 & 0.60 & 0.659 & 0.432 & 0.54 \\
\hline BDNF (pg/ml) & 7,107 (596.51) & $10,642(957.45)$ & $0.008^{\star}$ & 1.54 & $9,363(730.75)$ & 8,497 (943.75) & 0.304 & 0.36 & 12.47 & $0.003^{\star}$ & 6.46 \\
\hline CTHB (pg/ml) & $37,580(10,284)$ & $39,293(14,278)$ & 0.697 & 0.13 & $48,102(25,327)$ & $55,477(22,450)$ & 0.109 & 0.30 & 0.947 & 0.347 & 0.28 \\
\hline \multicolumn{12}{|l|}{ Cognitive } \\
\hline MoCA & $24.63(1.41)$ & 25.75 (2.38) & 0.229 & 0.56 & $24.50(2.00)$ & $25.75(2.71)$ & 0.380 & 0.40 & 0.006 & 0.938 & 0.07 \\
\hline DMS\% correct & $90.48(6.50)^{a}$ & $89.48(3.50)^{a}$ & 0.721 & 0.19 & 81.67 (16.23) & 80.00 (21.97) & 0.844 & 0.09 & 0.005 & 0.943 & 0.05 \\
\hline DMS latency (ms) & $4,857(1,648)^{\mathrm{a}}$ & $2,650(510.50)^{a}$ & $0.010^{\star}$ & 1.68 & $4,781(1,983)$ & 4,601 (3785) & 0.800 & 0.02 & 4.85 & 0.046 & 1.08 \\
\hline PAL (errors) & $22.14(20.93)^{a}$ & $19.86(11.44)^{\mathrm{a}}$ & 0.772 & 0.13 & $25.13(19.05)$ & $19.63(21.14)$ & 0.056 & 0.33 & 0.304 & 0.591 & 0.16 \\
\hline IED (errors) & $20.57(16.09)^{a}$ & $18.57(7.59)^{\mathrm{a}}$ & 0.774 & 0.16 & $17.75(9.04)$ & 19.50 (7.62) & 0.666 & 0.21 & 0.252 & 0.624 & 0.28 \\
\hline
\end{tabular}

${ }^{*} p<0.05$ FDR corrected across the whole table.

BMI, body mass index; BDI, Beck Depression Inventory; BDNF, brain-derived neurotropic factor; CBGT, cognitive behavioral group therapy; d, Cohen's D; dppc2, Cohen's D; DMS, delayed matching to sample; HADS, Hospital Anxiety and Depression Scale; IED, intradimensional/extradimensional shift; MoCA, Montreal Cognitive Assessment; PAL, Paired Associates Learning; PSQI, Pittsburgh Sleep Quality Index; $\mathrm{VO}_{2}$ max, maximum oxygen consumption.

Data are expressed as mean (SD).

${ }^{a}$ One missing value.

$p$-Values $<0.05$ were considered statistically significant and are represented in bold. 

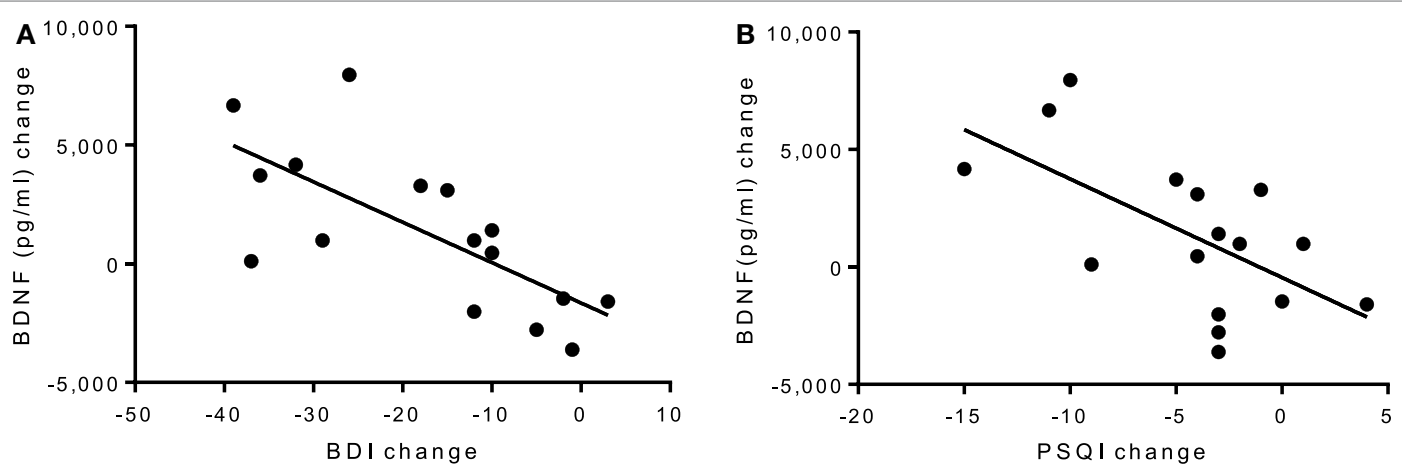

FIGURE 3 | (A) Linear regression of pre-post changes for BDI and PSQI scores against BDNF change, irrespective of group. (A) A significant negative correlation was found for (A) BDI scores and BDNF levels $\left(p=0.002, R^{2}=0.50\right)$ and $(\mathbf{B})$ PSQI scores and BDNF levels $\left(p=0.011, R^{2}=0.38\right)$, indicating that improvements in depression and sleep quality scores are associated with an increase in BDNF levels. BDI, Beck Depression Inventory; BDNF, brain-derived neurotropic factor; PSQI, Pittsburgh Sleep Quality Index.

plasticity and has been suggested to be the molecular mechanism that links synaptic plasticity and the homeostatic sleep response $(127,128)$. Rats administered higher levels of intracortical injections of BDNF during wakefulness show a stronger SWA response during subsequent sleep and stronger synaptic potentiation during waking. However, this effect is reversed when blocking BDNF during wakefulness (129). As such, one possible mechanisms of the improved sleep quality of patients in the exercise group may be the increase in plasma BDNF concentrations brought about via increased physical activity.

Our initial baseline comparison between MDD patients and healthy controls revealed that the MDD patients performed below the healthy controls on the hippocampal-dependent cognitive tests. These behavioral results complement our previous fMRI findings that explored the effects of an 8-week exercise intervention on hippocampal function during a memory encoding task, in low-active/low-fit MDD and healthy individuals (90). Despite no pre-post change in memory performance for either group, there was a consistent deactivation pattern in the hippocampus and other memory-related brain regions during the memory encoding process. This deactivation pattern was common among both the MDD and healthy groups, suggesting that exercise may have a generalized effect on brain function in low-active/low-fit individuals by enhancing neural network processing efficiency while still resulting in a greater mood effect for those suffering from MDD. Electroencephalographic studies have also found that active individuals showed less PFC activation and significantly faster reaction times compared to low-active individuals, indicating that physically active individuals require less cognitive resources and effortful task preparation that results in faster information processing speeds (130).

\section{Limitations}

The sample size of this feasibility study is small; thus, even though the exercise group experienced a concomitant decrease in depression severity and increase in plasma BDNF, our results must be considered preliminary. Another possible limitation is that our MDD samples were undergoing ADM, which may have affected our baseline comparison with healthy controls. However, to maximize the external validity of our results, we included medicated patients to replicate the typical patient seen in "realworld" clinical practice, to maximize the external validity of our results, including patients already on $\mathrm{ADM}$, actually increases the external validity. Furthermore, since our sample was composed of low-active MDD patients, we cannot be certain if the link between BDNF, depression, and sleep quality exists in high-fit/high-active MDD patients. There is a lack of reporting physical activity levels and cardiorespiratory fitness parameters in the MDD literature. Therefore, significant differences observed in studies that compare MDD to healthy individuals may be confounded by a sedentary lifestyle that may be more common in MDD. Future studies must compare "fit" vs. "low-fit" MDD groups to identify biological markers, independent of cardiorespiratory fitness and specific to MDD.

\section{Practical Implications}

This study adds to a growing body of literature suggesting the beneficial effects of exercise as an adjunct therapy for the treatment of depression. The effects of exercise may be twofold: first to reduce depressive symptoms and second to improve overall sleep quality. Our study adds to the existing literature by including a well-defined exercise prescription based on the validated metrics and titrated to an individual's fitness level. This combined aerobic and resistance exercise prescription, based on the minimum recommended dose, was well tolerated and adhered to throughout the 8 weeks by low-active MDD patients, giving health care practitioners potential guidelines for prescribing exercise to their patients. Such interventions can be added to clinical practice with minimal additional equipment or expertise and if needed could be approximated by having patients join existing exercise programs and classes, which may be available at private institutions such as a local gym.

\section{CONCLUSION}

The design of this feasibility study allowed for a "real-world" therapeutic approach that addresses effectiveness while also measuring biochemical markers shown to be altered in MDD. We provide preliminary evidence that exercise as an add-on to conventional antidepressant therapies may be more efficacious 
in treating MDD than no exercise. We also found that improvements in depression and sleep quality were associated with an increase in plasma BDNF concentration following exercise, providing a potential biological marker for treatment outcome. While the role of BDNF as a biomarker for depression and treatment outcome may be controversial (110), these results suggest the potential clinical importance of measuring peripheral BDNF concentrations and sleep quality in MDD patients to monitor changes over the course of treatment that may elucidate markers of clinical recovery.

\section{ETHICS STATEMENT}

Research Ethics Board (REB) at the University of Ontario Institute of Technology (UOIT): 11979 - (10-104). Lakeridge Health REB: 2011-024. All procedures were fully explained to each participant prior to study enrolment. All participants provided written consent.

\section{REFERENCES}

1. Ferrari A, Charlson F, Norman R, Patten SB, Freedman G, Murray CJ, et al. Burden of depressive disorders by country, sex, age, and year: findings from the global burden of disease study 2010. PLoS Med (2013) 10(11):e1001547. doi:10.1371/journal.pmed.1001547

2. World Health Organization. The Global Burden of Disease: 2004 Update. Geneva: WHO Press (2008). Available from: http://www.who.int/healthinfo/ global_burden_disease/2004_report_update/en/

3. Patten SB, Williams JVA, Lavorato DH, Wang JL, McDonald K, Bulloch AGM. Descriptive epidemiology of major depressive disorder in Canada in 2012. Can J Psychiatry (2015) 60(1):23-30. doi:10.1177/070674371506 000106

4. Patten SB, Wang JL, Williams JV, Currie S, Beck CA, Maxwell CJ, et al. Descriptive epidemiology of major depression in Canada. Can J Psychiatry (2006) 51(2):84-90. doi:10.1177/070674370605100204

5. Andrews G, Sanderson K, Corry J, Lapsley HM. Using epidemiological data to model efficiency in reducing the burden of depression. J Ment Health Policy Econ (2000) 3(4):175-86. doi:10.1002/mhp.96

6. Diverty B, Beaudet MP. Depression: an undertreated disorder. Health Rep (1997) 8(4):9-18.

7. Fava GA. Can long-term treatment with antidepressant drugs worsen the course of depression? J Clin Psychiatry (2003) 64(2):123-33.

8. Insel TR, Charney DS. Research on major depression: strategies and priorities. JAMA (2003) 289(23):3167. doi:10.1001/jama.289.23.3167

9. Rush AJ, Trivedi MH, Wisniewski SR, Nierenberg AA, Stewart JW, Warden D, et al. Acute and longer-term outcomes in depressed outpatients requiring one or several treatment steps: a STAR ${ }^{\star}$ D report. Focus (2008) 6(1):128-42. doi:10.1176/foc.6.1.foc 128

10. Fava M, Graves LM, Benazzi F, Scalia MJ, Iosifescu DV, Alpert JE, et al. A cross-sectional study of the prevalence of cognitive and physical symptoms during long-term antidepressant treatment. J Clin Psychiatry (2006) 67(11):1754-9. doi:10.4088/JCP.v67n1113

11. Paykel ES, Ramana R, Cooper Z, Hayhurst H, Kerr J, Barocka A. Residual symptoms after partial remission: an important outcome in depression. Psychol Med (1995) 25(6):1171-80. doi:10.1017/S0033291700033146

12. Moussavi S, Chatterji S, Verdes E, Tandon A, Patel V, Ustun B. Depression, chronic diseases, and decrements in health: results from the World Health Surveys.Lancet(2007)370(9590):851-8.doi:10.1016/S0140-6736(07)61415-9

13. McKinnon MC, Yucel K, Nazarov A, MacQueen GM. A meta-analysis examining clinical predictors of hippocampal volume in patients with major depressive disorder. J Psychiatry Neurosci (2009) 34(1):41-54.

14. Schmaal L, Veltman DJ, van Erp TGM, Sämann PG, Frodl T, Jahanshad N, et al. Subcortical brain alterations in major depressive disorder: findings from the ENIGMA Major Depressive Disorder working group. Mol Psychiatry (2016) 21(6):806-12. doi:10.1038/mp.2015.69

\section{AUTHOR CONTRIBUTIONS}

Study conception and design was performed by JG, PY, BM; acquisition of data was performed by JG, SC, HB; analysis and interpretation of data was performed by JG, BM, PY, SC, HB; drafting of manuscript was performed by JG, PY and $\mathrm{BM}$; and critical revision of the manuscript was performed by JG, PY, SC, $\mathrm{HB}$ and BM. All authors have read and approved this paper and have no conflicts of interest to report.

\section{ACKNOWLEDGMENTS}

The authors would like to thank Nancy Wilkinson, Ph.D., C. Psych., from Lakeridge Health Oshawa, for her assistance with the recruitment of the MDD group. We would also like to thank Joanne Free and Julia Green-Johnson, $\mathrm{PhD}$, from the University of Ontario Institute of Technology, for their assistance, technical expertise and guidance.

15. Videbech P, Ravnkilde B. Hippocampal volume and depression: a metaanalysis of MRI studies. Am J Psychiatry (2004) 161(11):1957. doi:10.1176/ appi.ajp.161.11.1957

16. Fairhall SL, Sharma S, Magnusson J, Murphy B. Memory related dysregulation of hippocampal function in major depressive disorder. Biol Psychiatry (2010) 85(3):499-503. doi:10.1016/j.biopsycho.2010.09.002

17. Milne AMB, MacQueen GM, Hall GBC. Abnormal hippocampal activation in patients with extensive history of major depression: an fMRI study. J Psychiatry Neurosci (2012) 37(1):28. doi:10.1503/jpn.110004

18. Sweeney J, Kmeic J, Kupfer D. Neuropsychologic impairments in bipolar and unipolar mood disorders on the CANTAB neurocognitive battery. Biol Psychiatry (2000) 48:674-85. doi:10.1016/S0006-3223(00)00910-0

19. Toki S, Okamoto Y, Onoda K, Matsumoto T, Yoshimura S, Kunisato Y, et al. Hippocampal activation during associative encoding of word pairs and its relation to symptomatic improvement in depression: a functional and volumetric MRI study. J Affect Disord (2014) 152-154:462-7. doi:10.1016/j. jad.2013.07.021

20. Zakzanis KK, Leach L, Kaplan E. On the nature and pattern of neurocognitive function in major depressive disorder. Neuropsychiatry Neuropsychol Behav Neurol (1998) 11(3):111-9.

21. Bocchio-Chiavetto L, Bagnardi V, Zanardini R, Molteni R, Gabriela Nielsen M, Placentino A, et al. Serum and plasma BDNF levels in major depression: a replication study and meta-analyses. World J Biol Psychiatry (2010) 11(6):763-73. doi:10.3109/15622971003611319

22. Brunoni AR, Lopes M, Fregni F. A systematic review and meta-analysis of clinical studies on major depression and BDNF levels: implications for the role of neuroplasticity in depression. Int J Neuropsychopharmacol (2008) 11(8):1169-80. doi:10.1017/S1461145708009309

23. Calabrese F, Molteni R, Racagni G, Riva MA. Neuronal plasticity: a link between stress and mood disorders. Psychoneuroendocrinology (2009) 34:S208-16. doi:10.1016/j.psyneuen.2009.05.014

24. Duman RS, Monteggia LM. A neurotrophic model for stress-related mood disorders. Biol Psychiatry (2006) 59(12):1116-27. doi:10.1016/j.biopsych. 2006.02.013

25. Duman RS, Malberg J, Nakagawa S, D'Sa C. Neuronal plasticity and survival in mood disorders. Biol Psychiatry (2000) 48(8):732-9. doi:10.1016/ S0006-3223(00)00935-5

26. Karege F, Vaudan G, Schwald M, Perroud N, La Harpe R. Neurotrophin levels in postmortem brains of suicide victims and the effects of antemortem diagnosis and psychotropic drugs. Brain Res Mol Brain Res (2005) 136(1-2):29-37. doi:10.1016/j.molbrainres.2004.12.020

27. Cunha C, Brambilla R, Thomas KL. A simple role for BDNF in learning and memory? Front Mol Neurosci (2010) 3:1. doi:10.3389/neuro.02.001.2010

28. Jacobs B, Van Praag H, Gage F. Adult brain neurogenesis and psychiatry: a novel theory of depression. Mol Psychiatry (2000) 5:262-9. doi:10.1038/ sj.mp. 4000712 
29. Serafini G. Neuroplasticity and major depression, the role of modern antidepressant drugs. World J Psychiatry (2012) 2(3):49-57. doi:10.5498/wjp. v2.i3.49

30. Wainwright SR, Galea LAM. The neural plasticity theory of depression: assessing the roles of adult neurogenesis and PSA-NCAM within the hippocampus. Neural Plast (2013) 2013:805497. doi:10.1155/2013/805497

31. Krishnadas R, Cavanagh J. Depression: an inflammatory illness? J Neurol Neurosurg Psychiatry (2012) 83(5):495-502. doi:10.1136/jnnp-2011-301779

32. Raison CL, Miller AH. Is depression an inflammatory disorder? Curr Psychiatry Rep (2011) 13(6):467-75. doi:10.1007/s11920-011-0232-0

33. Dantzer R, O'Connor JC, Freund GG, Johnson RW, Kelley KW. From inflammation to sickness and depression: when the immune system subjugates the brain. Nat Rev Neurosci (2008) 9(1):46-56. doi:10.1038/nrn2297

34. Dowlati Y, Herrmann N, Swardfager W, Liu H, Sham L, Reim EK, et al. A meta-analysis of cytokines in major depression. Biol Psychiatry (2010) 67(5):446-57. doi:10.1016/j.biopsych.2009.09.033

35. Hiles SA, Baker AL, de Malmanche T, Attia J. A meta-analysis of differences in IL- 6 and IL-10 between people with and without depression: exploring the causes of heterogeneity. Brain Behav Immun (2012) 26(7):1180-8. doi:10.1016/j.bbi.2012.06.001

36. Howren MB, Lamkin DM, Suls J. Associations of depression with C-reactive protein, IL-1, and IL-6: a meta-analysis. Psychosom Med (2009) 71(2):171-86. doi:10.1097/PSY.0b013e3181907cl

37. Liu Y, Ho RC-M, Mak A. Interleukin (IL)-6, tumour necrosis factor alpha (TNF- $\alpha$ ) and soluble interleukin-2 receptors (sIL-2R) are elevated in patients with major depressive disorder: a meta-analysis and meta-regression. J Affect Disord (2012) 139(3):230-9. doi:10.1016/j.jad.2011.08.003

38. Miller A, Raison C. The role of inflammation in depression: from evolutionary imperative to modern treatment target. Nat Rev Immunol (2016) 16(1):22-34. doi:10.1038/nri.2015.5

39. Schiepers OJG, Wichers MC, Maes M. Cytokines and major depression. Prog Neuropsychopharmacol Biol Psychiatry (2005) 29(2):201-17. doi:10.1016/j. pnpbp.2004.11.003

40. Zorrilla EP, Luborsky L, McKay JR, Rosenthal R, Houldin A, Tax A, et al. The relationship of depression and stressors to immunological assays: a metaanalytic review. Brain Behav Immun (2001) 15(3):199-226. doi:10.1006/ brbi. 2000.0597

41. Moon HY, Becke A, Berron D, Becker B, Sah N, Benoni G, et al. Runninginduced systemic cathepsin B secretion is associated with memory function. Cell Metab (2016) 24:332-40. doi:10.1016/j.cmet.2016.05.025

42. Babyak M, Blumenthal JA, Herman S, Khatri P, Doraiswamy M, Moore K, et al. Exercise treatment for major depression: maintenance of therapeutic benefit at 10 months. Psychosom Med (2000) 62(21):633-8. doi:10.1097/ 00006842-200009000-00006

43. Blumenthal JA, Babyak MA, Doraiswamy PM, Watkins L, Hoffman BM, Barbour KA, et al. Exercise and pharmacotherapy in the treatment of major depressive disorder. Psychosom Med (2007) 69(7):587. doi:10.1097/ PSY.0b013e318148c19a

44. Blumenthal JA, Babyak MA, Moore KA, Craighead WE, Herman S, Khatri P, et al. Effects of exercise training on older patients with major depression. Arch Intern Med (1999) 159(19):2349-56. doi:10.1001/archinte.159.19.2349

45. Hallgren M, Kraepelien M, Öjehagen A, Lindefors N, Zeebari Z, Kaldo V, et al. Physical exercise and internet-based cognitive-behavioural therapy in the treatment of depression: randomised controlled trial. Br J Psychiatry (2015) 207(3):227-34. doi:10.1192/bjp.bp.114.160101

46. Martinsen EW, Medhus A, Sandvik L. Effects of aerobic exercise on depression: a controlled study. Br Med J (1985) 291(6488):109. doi:10.1136/ bmj.291.6488.109

47. Stathopoulou G, Powers MB, Berry AC, Smits JAJ, Otto MW. Exercise interventions for mental health: a quantitative and qualitative review. Clin Psychol Sci Pract (2006) 13(2):179-93. doi:10.1111/j.1468-2850.2006.00021.x

48. Khatri P, Blumenthal JA, Babyak MA, Craighead WE, Herman S, Baldewicz T, et al. Effects of exercise training on cognitive functioning among depressed older men and women. J Aging Phys Act (2001) 9(1):43-57. doi:10.1123/ japa.9.1.43

49. Rethorst CD, Sunderajan P, Greer TL, Grannemann BD, Nakonezny PA, Carmody TJ, et al. Does exercise improve self-reported sleep quality in non-remitted major depressive disorder? Psychol Med (2013) 43(4):699-709. doi:10.1017/S0033291712001675
50. Conradi HJ, Ormel J, de Jonge P. Presence of individual (residual) symptoms during depressive episodes and periods of remission: a 3-year prospective study. Psychol Med (2011) 41(6):1165-74. doi:10.1017/S0033291710001911

51. Firth J, Stubbs B, Vancampfort D, Schuch F, Lagopoulos J, Rosenbaum S, et al. Effect of aerobic exercise on hippocampal volume in humans: a systematic review and meta-analysis. Neuroimage (2018) 166:230-8. doi:10.1016/j. neuroimage.2017.11.007

52. Kerling A, Kück M, Tegtbur U, Grams L, Weber-Spickschen S, Hanke A, et al. Exercise increases serum brain-derived neurotrophic factor in patients with major depressive disorder. JAffect Disord (2017) 215(215):152-5. doi:10.1016/j.jad.2017.03.034

53. Stubbs B, Chen L-J, Chang C-Y, Sun W-J, Ku P-W. Accelerometer-assessed light physical activity is protective of future cognitive ability: a longitudinal study among community dwelling older adults. Exp Gerontol (2017) 91:104-9. doi:10.1016/j.exger.2017.03.003

54. Cotman CW, Berchtold NC, Christie L. Exercise builds brain health: key roles of growth factor cascades and inflammation. Trends Neurosci (2007) 30(9):464-72. doi:10.1016/j.tins.2007.06.01

55. Colcombe SJ, Erickson KI, Scalf PE, Kim JS, Prakash R, McAuley E, et al. Aerobic exercise training increases brain volume in aging humans. J Gerontol A Biol Sci Med Sci (2006) 61(11):1166. doi:10.1093/gerona/61.11.1166

56. Erickson KI, Prakash RS, Voss MW, Chaddock L, Hu L, Morris KS, et al. Aerobic fitness is associated with hippocampal volume in elderly humans. Hippocampus (2009) 19(10):1030-9. doi:10.1002/hipo.20547

57. Erickson KI, Voss MW, Prakash RS, Basak C, Szabo A, Chaddock L, et al. Exercise training increases size of hippocampus and improves memory. Proc Natl Acad Sci U S A (2011) 108(7):3017-22. doi:10.1073/pnas. 1015950108

58. Voss MW, Heo S, Prakash RS, Erickson KI, Alves H, Chaddock L, et al. The influence of aerobic fitness on cerebral white matter integrity and cognitive function in older adults: results of a one-year exercise intervention. Hum Brain Mapp (2013) 34(11):2972-85. doi:10.1002/hbm.22119

59. Voss MW, Prakash RS, Erickson KI, Basak C, Chaddock L, Kim JS, et al. Plasticity of brain networks in a randomized intervention trial of exercise training in older adults. Front Aging Neurosci (2010) 2:32. doi:10.3389/ fnagi.2010.00032

60. Devine JM, Zafonte RD. Physical exercise and cognitive recovery in acquired brain injury: a review of the literature. $P M R$ (2009) 1(6):560. doi:10.1016/j. pmrj.2009.03.015

61. Mossberg KA, Amonette WE, Masel BE. Endurance training and cardiorespiratory conditioning after traumatic brain injury. J Head Trauma Rehabil (2010) 25(3):173. doi:10.1097/HTR.0b013e3181dc98ff

62. Pajonk FG, Wobrock T, Gruber O, Scherk H, Berner D, Kaizl I, et al. Hippocampal plasticity in response to exercise in schizophrenia. Arch Gen Psychiatry (2010) 67(2):133. doi:10.1001/archgenpsychiatry.2009.193

63. Henson J, Yates T, Edwardson CL, Khunti K, Talbot D, Gray LJ, et al. Sedentary time and markers of chronic low-grade inflammation in a high risk population. PLoS One (2013) 8(10):e78350. doi:10.1371/journal.pone.0078350

64. Zoladz JA, Pilc A, Majerczak J, Grandys M, Zapart-Bukowska J, Duda K. Endurance training increases plasma brain-derived neurotrophic factor concentration in young healthy men. J Physiol Pharmacol (2008b) 59(Suppl 7): $119-32$.

65. American Psychiatric Association. Diagnostic and Statistical Manual of Mental Disorders (Fourth). Washington, DC: American Psychiatric Publishing, Inc (1994).

66. Beck A, Steer R, Brown G. BDI-II. Beck Depression Inventory Second Edition. Manual. San Antonio: Psychological Corporation (1996). Available from: https://scholar.google.ca/scholar?q=beck+depression+second+edition+II+1996\&btnG $=\&$ hl $=$ en\&as_sdt $=0 \% 2$ C5\#0

67. Dennis ML, Chan YF, Funk RR. Development and validation of the GAIN Short Screener (GSS) for internalizing, externalizing and substance use disorders and crime/violence problems among adolescents and adults. Am J Addict (2006) 15(s1):80-91. doi:10.1080/10550490601006055

68. Beck AT, Steer RA, Ball R, Ranieri WF. Comparison of Beck depression inventories-IA and-II in psychiatric outpatients. JPers Assess (1996) 67(3):588-97. doi:10.1207/s15327752jpa6703_13

69. Zigmond AS, Snaith RP. The Hospital Anxiety and Depression Scale. Acta Psychiatr Scand (1983) 67(6):361-70. doi:10.1111/j.1600-0447.1983. tb09716.x 
70. Bjelland I, Dahl AA, Haug TT, Neckelmann D. The validity of the Hospital Anxiety and Depression Scale. JPsychosom Res (2002) 52(2):69-77. doi:10.1016/S0022-3999(01)00296-3

71. Buysse DJ, Reynolds CF III, Monk TH, Berman SR, Kupfer DJ. The Pittsburgh Sleep Quality Index: a new instrument for psychiatric practice and research. Psychiatry Res (1989) 28(2):193-213. doi:10.1016/0165-1781(89)90047-4

72. Fray PJ, Robbins TW. CANTAB battery: proposed utility in neurotoxicology. Neurotoxicol Teratol (1996) 18(4):499-504. doi:10.1016/08920362(96)00027-X

73. Fowler KS, Saling MM, Conway EL, Semple JM, Louis WJ. Computerized delayed matching to sample and paired associate performance in the early detection of dementia. Appl Neuropsychol (1995) 2(2):72-8. doi:10.1207/ s15324826an0202_4

74. Levaux M-N, Potvin S, Sepehry AA, Sablier J, Mendrek A, Stip E. Computerized assessment of cognition in schizophrenia: promises and pitfalls of CANTAB. Eur Psychiatry (2007) 22(2):104-15. doi:10.1016/j.eurpsy. 2006.11.004

75. de Rover M, Pironti VA, McCabe JA, Acosta-Cabronero J, Arana FS, MoreinZamir S, et al. Hippocampal dysfunction in patients with mild cognitive impairment: a functional neuroimaging study of a visuospatial paired associates learning task. Neuropsychologia (2011) 49(7):2060-70. doi:10.1016/j. neuropsychologia.2011.03.037

76. Heinzel A, Northoff G, Boeker H, Boesiger P, Grimm S. Emotional processing and executive functions in major depressive disorder: dorsal prefrontal activity correlates with performance in the intra-extra dimensional set shift. Acta Neuropsychiatr (2010) 22(6):269-79. doi:10.1111/j.1601-5215.2010.00494.x

77. Porter RJ, Gallagher P, Thompson JM, Young AH. Neurocognitive impairment in drug-free patients with major depressive disorder. $\mathrm{Br} J$ Psychiatry (2003) 182:214-20. doi:10.1192/BJP.182.3.214

78. Nasreddine ZS, Phillips NA, Bédirian V, Charbonneau S, Whitehead V, Collin I, et al. The Montreal Cognitive Assessment, MoCA: a brief screening tool for mild cognitive impairment. J Am Geriatr Soc (2005) 53(4):695-9. doi:10.1111/j.1532-5415.2005.53221.x

79. Beekley MD, Brechue WF, Dehoyos DV, Garzarella L, Werber-Zion G, Pollock ML. Cross-validation of the YMCA submaximal cycle ergometer test to predict $\mathrm{VO}_{2}$ max. Res Q Exerc Sport (2004) 75(3):337-42. doi:10.1080 /02701367.2004.10609165

80. Golding LA, Myers CR, Sinning WE, editors. Y's Way to Physical Fitness: The Complete Guide to Fitness Testing and Instruction. Champaign, IL: Human Kinetics Publishers, Inc. (1989).

81. Pescatello LS; American College of Sports Medicine. ACSM's Guidelines for Exercise Testing and Prescription. Philadelphia, PA: Wolters Kluwer/ Lippincott Williams \& Wilkins Health (2014).

82. Tremblay MS, Warburton DER, Janssen I, Paterson DH, Latimer AE, Rhodes RE, et al. New Canadian physical activity guidelines. Appl Physiol Nutr Metab (2011) 36(1):36-46. doi:10.1139/H11-009

83. Garber CE, Blissmer B, Deschenes MR, Franklin BA, Lamonte MJ, Lee IM, et al. American College of Sports Medicine position stand. Quantity and quality of exercise for developing and maintaining cardiorespiratory, musculoskeletal, and neuromotor fitness in apparently healthy adults: guidance for prescribing exercise. Med Sci Sports Exerc (2011) 43(7):1334-59. doi:10.1249/ MSS.0b013e318213fefb

84. Stanton R, Reaburn P. Exercise and the treatment of depression: a review of the exercise program variables. J Sci Med Sports (2014) 17(2):177-82. doi:10.1016/j.jsams.2013.03.010

85. Kerling A, Tegtbur U, Gützlaff E, Kück M, Borchert L, Ates Z, et al. Effects of adjunctive exercise on physiological and psychological parameters in depression: a randomized pilot trial. J Affect Disord (2015) 177:1-6. doi:10.1016/j. jad.2015.01.006

86. Kerling A, von Bohlen A, Kück M, Tegtbur U, Grams L, Haufe S, et al. Exercise therapy improves aerobic capacity of inpatients with major depressive disorder. Brain Behav (2016) 6(6):e00469. doi:10.1002/brb3.469

87. Cooney G. Exercise for depression. J Evid Based Med (2013) 6(4):307-8. doi:10.1111/jebm.12076

88. Smith PJ, Blumenthal JA, Hoffman BM, Cooper H, Strauman TA, WelshBohmer K, et al. Aerobic exercise and neurocognitive performance: a meta-analytic review of randomized controlled trials. Psychosom Med (2010) 72(3):239-52. doi:10.1097/PSY.0b013e3181d14633
89. Schuch FB, Vancampfort D, Richards J, Rosenbaum S, Ward PB, Stubbs B. Exerciseas a treatment for depression: a meta-analysis adjusting for publication bias. J Psychiatr Res (2016) 77:42-51. doi:10.1016/j.jpsychires.2016.02.023

90. Gourgouvelis J, Yielder P, Murphy B. Exercise promotes neuroplasticity in both healthy and depressed brains: an fMRI pilot study. Neural Plast (2017) 2017:1-13. doi:10.1155/2017/8305287

91. Morris SB. Estimating Effect Size from the Pretest-Posttest-Control Design (2003). Available from: http://faculty.cas.usf.edu/mbrannick/papers/conf/ esppc_siop03.pdf

92. Morris SB. Pre-Post-Control Effect Size 1 Estimating Effect Size from the Pretest-Posttest-Control Design. (2003). Available from: http://faculty.cas.usf. edu/mbrannick/papers/conf/esppc_siop03.pdf

93. Pilu A, Sorba M, Hardoy MC, Floris AL, Mannu F, Seruis ML, et al. Efficacy of physical activity in the adjunctive treatment of major depressive disorders: preliminary results. Clin Pract Epidemiol Ment Health (2007) 3:8. doi:10.1186/1745-0179-3-8

94. Schuch FB, Vasconcelos-Moreno MP, Borowsky C, Fleck MP. Exercise and severe depression: preliminary results of an add-on study. J Affect Disord (2011) 133(3):615-8. doi:10.1016/j.jad.2011.04.030

95. Cotman CW, Berchtold NC. Exercise: a behavioral intervention to enhance brain health and plasticity. Trends Neurosci (2002) 25(6):295-301. doi:10.1016/S0166-2236(02)02143-4

96. Marlatt MW, Potter MC, Lucassen PJ, van Praag H. Running throughout middle-age improves memory function, hippocampal neurogenesis, and BDNF levels in female C57BL/6J mice. Dev Neurobiol (2012) 72(6):943-52. doi:10.1002/dneu.22009

97. Pereira AC, Huddleston DE, Brickman AM, Sosunov AA, Hen R, McKhann GM, et al. An in vivo correlate of exercise-induced neurogenesis in the adult dentate gyrus. Proc Natl Acad Sci U S A (2007) 104(13):5638. doi:10.1073/ pnas.0611721104

98. van Praag H, Kempermann G, Gage FH. Running increases cell proliferation and neurogenesis in the adult mouse dentate gyrus. Nat Neurosci (1999) 2(3):266-70. doi:10.1038/6368

99. Dietrich MO, Andrews ZB, Horvath TL. Exercise-induced synaptogenesis in the hippocampus is dependent on UCP2-regulated mitochondrial adaptation. J Neurosci (2008) 28(42):10766-71. doi:10.1523/JNEUROSCI.274408.2008

100. Lopez-Lopez C, LeRoith D, Torres-Aleman I. Insulin-like growth factor I is required for vessel remodeling in the adult brain. Proc Natl Acad Sci U S A (2004) 101(26):9833-8. doi:10.1073/pnas.0400337101

101. Redila VA, Christie BR. Exercise-induced changes in dendritic structure and complexity in the adult hippocampal dentate gyrus. Neuroscience (2006) 137(4):1299-307. doi:10.1016/j.neuroscience.2005.10.050

102. Yau S-Y, Lau BW-M, Tong J-B, Wong R, Ching Y-P, Qiu G, et al. Hippocampal neurogenesis and dendritic plasticity support running-improved spatial learning and depression-like behaviour in stressed rats. PLoS One (2011) 6(9):e24263. doi:10.1371/journal.pone. 0024263

103. van Praag H, Shubert T, Zhao C, Gage FH. Exercise enhances learning and hippocampal neurogenesis in aged mice. J Neurosci (2005) 25(38):8680-5. doi:10.1523/JNEUROSCI.1731-05.2005

104. Dinoff A, Herrmann N, Swardfager W, Lanctôt KL. The effect of acute exercise on blood concentrations of brain-derived neurotrophic factor in healthy adults: a meta-analysis. Eur J Neurosci (2017) 46(1):1635-46. doi:10.1111/ ejn. 13603

105. Ferris LT, Williams JS, Shen C-L. The effect of acute exercise on serum brain-derived neurotrophic factor levels and cognitive function. $\mathrm{Med} S \mathrm{Sc}$ Sports Exerc (2007) 39(4):728-34. doi:10.1249/mss.0b013e31802f04c7

106. Heyman E, Gamelin F-X, Goekint M, Piscitelli F, Roelands B, Leclair E, et al. Intense exercise increases circulating endocannabinoid and BDNF levels in humans - possible implications for reward and depression. Psychoneuroendocrinology(2012)37(6):844-51.doi:10.1016/j.psyneuen.2011. 09.017

107. Gustafsson G, Lira CM, Johansson J, Wisén A, Wohlfart B, Ekman R, et al. The acute response of plasma brain-derived neurotrophic factor as a result of exercise in major depressive disorder. Psychiatry Res (2009) 169(3):244-8. doi:10.1016/j.psychres.2008.06.030

108. Laske C, Banschbach S, Stransky E, Bosch S, Straten G, Machann J, et al. Exercise-induced normalization of decreased BDNF serum concentration 
in elderly women with remitted major depression. Int J Neuropsychopharmacol (2010) 13(5):595-602. doi:10.1017/S1461145709991234

109. Håkansson K, Ledreux A, Daffner K, Terjestam Y, Bergman P, Carlsson R, et al. BDNF responses in healthy older persons to 35 minutes of physical exercise, cognitive training, and mindfulness: associations with working memory function. J Alzheimers Dis (2016) 55(2):645-57. doi:10.3233/JAD160593

110. Toups MSP, Greer TL, Kurian BT, Grannemann BD, Carmody TJ, Huebinger R, et al. Effects of serum Brain Derived Neurotrophic Factor on exercise augmentation treatment of depression. J Psychiatr Res (2011) 45(10):1301-6. doi:10.1016/j.jpsychires.2011.05.002

111. Balducci S, Zanuso S, Nicolucci A, Fernando F, Cavallo S, Cardelli P, et al. Anti-inflammatory effect of exercise training in subjects with type 2 diabetes and the metabolic syndrome is dependent on exercise modalities and independent of weight loss. Nutr Metab Cardiovasc Dis (2010) 20(8):608-17. doi:10.1016/j.numecd.2009.04.015

112. de Meirelles LR, Matsuura C, Resende Ade C, Salgado AA, Pereira NR, Coscarelli PG, et al. Chronic exercise leads to antiaggregant, antioxidant and anti-inflammatory effects in heart failure patients. Eur J Prev Cardiol (2014) 21(10):1225-32. doi:10.1177/2047487313491662

113. Pedersen BK. The anti-inflammatory effect of exercise: its role in diabetes and cardiovascular disease control. Essays Biochem (2006) 42:105-17. doi:10.1042/bse0420105

114. Batista ML, Batista Júnior ML, Lopes RD, Seelaender MCL, Lopes AC. Antiinflammatory effect of physical training in heart failure: role of TNF- $\alpha$ and IL-10. Arq Bras Cardiol (2009) 93(6):643-51, 692-700.

115. Petersen AMW, Pedersen BK. The anti-inflammatory effect of exercise. J Appl Physiol (2005) 98(4):1154-62. doi:10.1152/japplphysiol.00164.2004

116. Schmitt K, Holsboer-Trachsler E, Eckert A. BDNF in sleep, insomnia, and sleep deprivation. Ann Med (2016) 48(1-2):42-51. doi:10.3109/07853890. 2015.1131327

117. Mendlewicz J. Sleep disturbances: core symptoms of major depressive disorder rather than associated or comorbid disorders. World J Biol Psychiatry (2009) 10(4):269-75. doi:10.3109/15622970802503086

118. Palagini L, Baglioni C, Ciapparelli A, Gemignani A, Riemann D. REM sleep dysregulation in depression: state of the art. Sleep Med Rev (2013) 17(5):377-90. doi:10.1016/j.smrv.2012.11.001

119. Borbély AA, Tobler I, Loepfe M, Kupfer DJ, Ulrich RF, Grochocinski V, et al. All-night spectral analysis of the sleep EEG in untreated depressives and normal controls. Psychiatry Res (1984) 12(1):27-33. doi:10.1016/ 0165-1781(84)90135-5

120. Hoffmann R, Hendrickse W, Rush AJ, Armitage R. Slow-wave activity during non-REM sleep in men with schizophrenia and major depressive disorders. Psychiatry Res (2000) 95(3):215-25. doi:10.1016/S0165-1781(00) 00181-5

121. Gorgoni M, D’Atri A, Lauri G, Rossini PM, Ferlazzo F, De Gennaro L. Is sleep essential for neural plasticity in humans, and how does it affect motor and cognitive recovery? Neural Plast (2013) 2013:103949. doi:10.1155/2013/103949

122. Huber R, Ghilardi MF, Massimini M, Tononi G. Local sleep and learning. Nature (2004) 430(6995):78-81. doi:10.1038/nature02663

123. Allen S, Dawbarn D. Clinical relevance of the neurotrophins and their receptors. Clin Sci (2006) 110:175-91. doi:10.1042/CS20050161

124. Autry AE, Monteggia LM. Brain-derived neurotrophic factor and neuropsychiatric disorders. Pharmacol Rev (2012) 64(2):238-58. doi:10.1124/ pr.111.005108

125. Kubo T, Nonomura T, Enokido Y, Hatanaka H. Brain-derived neurotrophic factor (bdnf) can prevent apoptosis of rat cerebellar granule neurons in culture. Dev Brain Res (1995) 85(2):249-58. doi:10.1016/0165-3806(94)00220-T

126. Li N, Liu G. The novel squamosamide derivative FLZ enhances BDNF/TrkB/ CREB signaling and inhibits neuronal apoptosis in APP/PS1 mice. Acta Pharmacol Sin (2010) 31(3):265-72. doi:10.1038/aps.2010.3

127. Bachmann V, Klein C, Bodenmann S, Schäfer N, Berger W, Brugger P, et al. The BDNF Val66Met polymorphism modulates sleep intensity: EEG frequency- and state-specificity. Sleep (2012) 14(3):540-5. doi:10.5665/ sleep. 1690

128. Huber R, Tononi G, Cirelli C. Exploratory behavior, cortical BDNF expression, and sleep homeostasis. Sleep (2007) 30(2):129-39. doi:10.1093/ sleep/30.2.129

129. Faraguna U, Vyazovskiy VV, Nelson AB, Tononi G, Cirelli C. A causal role for brain-derived neurotrophic factor in the homeostatic regulation of sleep. J Neurosci (2008) 28(15):4088-95. doi:10.1523/JNEUROSCI.5510-07.2008

130. Berchicci M, Lucci G, Di Russo F. Benefits of physical exercise on the aging brain: the role of the prefrontal cortex. J Gerontol A Biol Sci Med Sci (2013) 68(11):1337-41. doi:10.1093/gerona/glt094

Conflict of Interest Statement: The authors declare that there is no conflict of interest regarding the publication of this paper.

Copyright (ङ 2018 Gourgouvelis, Yielder, Clarke, Behbahani and Murphy. This is an open-access article distributed under the terms of the Creative Commons Attribution License (CC BY). The use, distribution or reproduction in other forums is permitted, provided the original author(s) and the copyright owner are credited and that the original publication in this journal is cited, in accordance with accepted academic practice. No use, distribution or reproduction is permitted which does not comply with these terms. 